\title{
The effect of the health poverty alleviation project on the burden of congenital heart disease for Kizilsu Kirghiz Autonomous Prefecture, China
}

\section{Cheng Zhang}

the First Affiliated Hospital of Nanjing Medical University

Chunyu Li

the First Affiliated Hospital of Nanjing Medical University

Aizezi Gulisitan

Kizilsu Kirghiz Autonomous Prefecture People's Hospital

\section{Ainiwa Milinuer}

Kizilsu Kirghiz Autonomous Prefecture People's Hospital

\section{Zhenhai Zhang}

Kizilsu Kirghiz Autonomous Prefecture People's Hospital

\section{Xiangping Nan}

Kizilsu Kirghiz Autonomous Prefecture People's Hospital

\section{Xianggui Xu}

Kizilsu Kirghiz Autonomous Prefecture People's Hospital

Yan Chen ( $\nabla$ chenyandoc@163.com )

the First Affiliated Hospital of Nanjing Medical University

\section{Research Article}

Keywords: China, health poverty alleviation, congenital heart disease, impoverishment, project

Posted Date: June 25th, 2021

DOI: https://doi.org/10.21203/rs.3.rs-622848/v1

License: (1) (1) This work is licensed under a Creative Commons Attribution 4.0 International License. Read Full License 
The effect of the health poverty alleviation project on the burden of congenital heart disease for Kizilsu Kirghiz Autonomous Prefecture, China

Cheng Zhang ${ }^{1, \#}$, Chunyu Li ${ }^{2, \#}$, Aizezi Gulisitan ${ }^{3}$, Ainiwa Milinuer ${ }^{4}$, Zhenhai Zhang ${ }^{4}$, Xiangping $\mathrm{Nan}^{4}$, Xianggui $\mathrm{Xu}^{4}$, Yan $\mathrm{Chen}^{5,6,7^{*}}$

${ }^{1}$ Department of Science and Technology, the First Affiliated Hospital of Nanjing Medical University, Nanjing 210029, China.

${ }^{2}$ Intensive Care Unit, the First Affiliated Hospital of Nanjing Medical University, Nanjing 210029, China.

${ }^{3}$ Department of Medical Records, Kizilsu Kirghiz Autonomous Prefecture People's Hospital, Artux 845350, China.

${ }^{4}$ Department of Medical Section, Kizilsu Kirghiz Autonomous Prefecture People's Hospital, Artux 845350, China.

${ }^{5}$ Emergency Management Department, School of Health Policy \& Management, Nanjing Medical University, Nanjing, Jiangsu 211166, China.

${ }^{6}$ Research Institute of Health Jiangsu, Nanjing Medical University, Nanjing, Jiangsu 211166, China. ${ }^{7}$ Outpatient \& Emergency Management Department, the First Affiliated Hospital of Nanjing Medical University, Nanjing, Jiangsu 210029, China.

${ }^{*}$ Correspondence: chenyandoc@163.com

${ }^{5}$ Emergency Management Department, School of Health Policy \& Management, Nanjing Medical University, Nanjing, Jiangsu 211166, China.

${ }^{6}$ Research Institute of Health Jiangsu, Nanjing Medical University, Nanjing, Jiangsu 211166, China. ${ }^{7}$ Outpatient \& Emergency Management Department, the First Affiliated Hospital of Nanjing Medical University, Nanjing, Jiangsu 210029, China.

\# These authors contributed equally to this work.

Full list author information is available at the end of the article 


\begin{abstract}
Background: The implement of the health poverty alleviation project is a very important initiative for reducing poverty. Although previous studies have analyzed the effect of impoverishment, few papers compared the differences of the economy and the morbidity after the implement of the health poverty alleviation project in China.

Methods: To analyze the effect of the health poverty alleviation project on the burden of congenital heart disease, we collected the hospitalization expenses and epidemiology data of congenital heart disease in Kizilsu Kirghiz Autonomous Prefecture from 2016 to 2018, in which the health poverty alleviation project was implemented. SPSS 23.0 and Disability Adjusted Life Years were applied to analyze the burden of the disease.
\end{abstract}

Results: Our study found that the prevalence rate of congenital heart disease was increasing year by year. In total, 4719 poor people enjoyed the welfare of health poverty alleviation in the People's Hospital of Kezhou. The out-of-pocket ratio was only $2.25 \%$. After the health poverty alleviation project, the loss of Disability Adjusted Life Years was smaller and smaller. 24 sessions have been carried out to operate 208 patients with congenital heart disease, all of which have been successful. Conclusions: This study found that the health poverty alleviation project not only bringed healthy life expectancy to poor families, but also greatly reduces their financial burden.

Keywords: China; health poverty alleviation; congenital heart disease; impoverishment; project

\title{
Background
}

Poverty is one of the most serious problems in the world. Reducing and eradicating poverty is an important task and a realistic need for every country in the world, especially backward countries[1,2]. Comprehensively lift out of poverty is also an important strategic goal of our Chinese country. In November 2013, a strategy of "precision poverty alleviation" was proposed in China, in which health poverty alleviations are important components[3]. The implementation of the health poverty alleviation projects ensure that poor areas and poor people could better enjoy basic medical and health services, preventing poverty due to illness. This is conducive to the promotion of "Healthy China 2030" construction[4, 5].

"Three districts, three states" are the deep poverty-stricken areas in our country. They are also the main battleground for developing health poverty alleviations. "Three districts" refer to Tibet, the four provinces of Tibet (Qinghai, Sichuan, Gansu, Yunnan), the four southern regions (Hetian region, Aksu region, Kashgar region, Kizilsu Kirghiz Autonomous Region). These areas own a large number of poor people with poor natural conditions, weak economic foundation, belonging to the concentrated series of special hardship areas[6]. In 2016, "medical group" assistance for medical personnel was put forward to support the development of medical and health services in Xinjiang, especially in the southern Xinjiang region[7].

The implementation of medical counterpart support in the eastern and western regions is an important measure to the health poverty alleviation and to reduce poverty caused by diseases and return to poverty in the border areas[8]. Jiangsu Province, as one of the first seven "medical group", selected health aid talents to develop health poverty alleviation in various hospitals of Kizilsu Kirghiz Autonomous prefecture. In order to improve the health literacy of the masses, Jiangsu "group-style" medical assistance actively promoted the contact between the medical staff of the hospital and the primary health care workers[9]. Big bazaar and spring bud action of Jiangsu have 
been carried out. Health consultation, health science, and disease screening are all for free. As one of the health poverty alleviations, the Runxin project are carried out for free in many kinds of heart diseases. Since 2016, 24 sessions have been carried out to operate 208 patients with heart disease, all of which have been successful. Besides, many new treatments have also been implemented, such as charitable medical assistance, the introduction of the "Golden Mantis Life Light Love Relief Fund", the treatment of patients with congenital heart disease, coronary heart disease for heart surgery difficult family patients, the assistance of malignant tumor patients.

The "medical group" of Jiangsu adhere to the basic strategy of precision poverty alleviation and priority to support the work of health poverty alleviation project, increasing projects and capital investment in Kizilsu Kirghiz Autonomous prefecture. The implementation of health poverty alleviation project could better increase the strength and cohesion of the masses of all ethnic groups. It also contributes to maintaining social stability and long-term stability.

The purpose of this paper is to analyze the medical expenses of patients with congenital heart disease (CHD) in Kizilsu Kirghiz Autonomous prefecture, Xinjiang province. And apply the Disability Adjusted Life Years (DALY) to analyze the burden of the disease, thus evaluating the impact of the health poverty alleviation project.

\section{Methods}

\section{Study Design}

This study was designed to analyze the burden of the economy and the morbidity in Kizilsu Kirghiz Autonomous Prefecture before and after the implement of the health poverty alleviation project.

\section{Study area}

Kizilsu Kirghiz Autonomous Prefecture is the study area, a city located in west of China in the westernmost country of Xinjiang, which is one of the extreme backward regions for combatting poverty in China (Figure 1). The notice that the State Council Leading Group Office issued on the implementation of guidelines for supporting poverty alleviation in poverty-stricken regions[10].

\section{Data collected}

From 2016, "medical group" policy to Xinjiang was implemented by the Organization Department of the Central Committee of the CPC and the State Health Planning Commission, thus strengthening health poverty alleviation in poverty-stricken countries. To evaluate the effect of the project, we chose 2016 to 2018 as the targeted period. The hospitalization expenses and epidemiology data of congenital heart disease in Kizilsu Kirghiz Autonomous Prefecture were collected from 2016 to 2018 in the Statistic bureau of Xinjiang uygur autonomous region[11].

\section{Disability Adjusted Life Years (DALY)}

DALY means that the actual loss of life resulting from illness or death at each age is modified by a set of parameters and the standard life expectancy of the corresponding age[12]. Among them, D means Deactivation Weight (0-1, value 1 at death, Other age groups take values of 0.323$), \Upsilon$ means discount rate ( 0.03 in global disease burden), c means age weight adjustment factor $(0.1658$ in global disease burden analysis), $\beta$ means age function parameters ( 0.04 in global disease burden analysis), $\alpha$ means age of death or disability, L means time lost or The duration of the disability, 
each of which is determined by the World Health Organization's WHO GBD.

$$
\frac{D c e^{-\beta \alpha}}{(\beta+\gamma)^{2}}\left\{e^{-(\beta+y) L}[1+(\beta+\gamma)(L+\alpha)]-[1+(\beta+\gamma) \alpha]\right\}
$$

\section{Statistical analyses}

All data were conducted with SPSS 23.0. Quantitative statistics with normal distribution were expressed as mean \pm standard deviation ( $\overline{\mathrm{X}} \pm \mathrm{S}$ ). Student's $\mathrm{t}$ test was used to analyze means between groups. For all analyses, we considered 2-tailed $P$ values $<0.05$ as a significance.

\section{Results}

\section{Epidemiological data}

According to the statistic bureau of Xinjiang Uygur Autonomous Region, the total population of Xinjiang Uygur Autonomous Region in 2016 were 32,148, and the total population of congenital heart disease (CHD) were 45. The total population in 2017 were 33,320, and the number of CHD were 84 . In 2018, the total population were 41,879, with 141 people with CHD. The prevalence of CHD in $2016-2018$ was $0.14 \%, 0.25 \%$ and $0.34 \%$, respectively (Table1). It shows that the prevalence rate of CHD is increasing year by year.

\section{The benefits of poverty reduction policy}

In 2018, 4719 poor people enjoyed the welfare of health poverty alleviation in the People's Hospital of Kezhou. The cost of total was 9202.91 RMB. Among those, the amount of self-funded was 207.35 RMB. The out-of-pocket ratio was only $2.25 \%$ (Figure2).

\section{The analyze of Disability Adjusted Life Years (DALY)}

Collecting information on the age, sex, duration of illness, etc., and living expectancy for all age groups recommended by the Who Organization of the World Health Organization. Table 2 shows that there were total 271 hospitalized with CHD with 97 males $(35.79 \%)$ and 174 females (64.21\%) from January 2016 to December 2018. The average DALY is 4.57. Table 3 shows that the DALY of males' and females' is 3.72 and 5.11, respectively. The number of 0-14 group is highest each year, and the DALY is also the largest. The second largest number is the 30-44 group.

\section{The benefits of Runxin project}

Due to the backwardness of Kizilsu Kirghiz Autonomous Prefecture, patients with CHD could not be treated in time. Since 2016, 24 sessions have been carried out to operate 208 patients with heart disease, all of which have been successful (Patients with Incomplete information were excluded in the study). The results show that the largest amounts of Runxin project are made up of 0-14 group. The second largest population are the 30-44 group $(P<0.0001)$ (Table4).

\section{Discussion}

Kizilsu Kirghiz Autonomous Prefecture is located in pamirs plateau, in which peasants live at high altitudes for a long time. Rates of CHD are very high in the plateau[13]. In our study, the prevalence of CHD in Xinjiang has been increasing year by year. Due to the backward economic and medical technology in Kezhou, many patients with CHD missed opportunity to achieve timely and effective treatment, even lost their lives. It imposed a serious financial burden on poor families. 
After the implement of the health poverty alleviation project, those poor families were rid themselves of financial burden and mental stress with the free of charge.

Economic burden to households due to out-of-pocket expenditure (OOPE) is large in many developing countries and OOPE medical expenses often lead to catastrophic expenditure and impoverishment in low- and middle-income countries[14]. Besides, high OOPE could be an obstacle to health care access and treatment compliance, thus affecting patients' health[15]. Due to the high medical costs and the lack of the medical technology, patients had to go to superior hospital for surgical operations. Since the implementation of Jiangsu's "medical group" in 2016, medical specialists went to Kezhou for surgical operations with endowments, thus reducing the burden of diseases. CHD patients have been treated in time, and the proportion of OOPE has gradually decreased each year in our study. With the help of health poverty alleviation project, the burden on the poor families has been less and less. These poor families truly enjoyed the better bounty and convenience.

Improvement to treatment is important to expand the potential health benefits of screening[16]. In our study, we used DALY as an indicator to calculated the lost due to CHD. According to our DALY results, the 0-14 group owned the largest number of CHD patients with the highest DALY. To these children, they were all underage. They had not yet work and they had no ability to make money, which could lead to a heavy financial burden in a family. The number of 30-44 group was the second most population with the second largest DALY. Those patients were all young adults. They made the main money for their family. The economy of their family would be seriously affected if they were sick. It might lead to serious loss of the economic even to the decline living standards. Findings had an important policy implication to protect poor youth and late middle-aged population. As those population enters old age, the high financial burden they faced could exacerbate persistent socioeconomic health disparity among older people[17]. Under the health poverty alleviation project, the loss of DALY was smaller and smaller. This suggested that this project not only bringed healthy life expectancy to poor patients, but also greatly reduced their financial burden.

Before 2016, the overall medical level was very low in the Kizilsu Kirghiz Autonomous Prefecture. The local residents could have to go to Urumqi for treatment of CHD. The long journey and high cost caused many families to return to poverty or be poor due to disease. To solve these problem, Runxin project had been launched by "group-style" medical assistance of Jiangsu in the Kizilsu Kirghiz Autonomous Prefecture. The cost of operation was supported by medical insurance, headquarter of Jiangsu in Xinjiang and Kezhou people's hospital. Since 2016, 24 sessions have been carried out to operate 208 patients with heart disease, all of which have been successful. 0-14 group was the most supported in different age group. 30-44 group was the second most supported. The burden of diseases and the financial burden of families have been greatly reduced.

Nowadays, although some patients benefit from the policy, there are still some problems to be improved. Firstly, many patients are not familiar with the program, most of them know it only from doctors. With the development of society, news media undertakes not only the task of publicity but the one of supervision. Local hospitals could use news media to publicize the health poverty alleviation, which is helpful for the transparency of the poverty spending. To do the effort better, not only public hospitals but also government, news media and the mass should join us in the health poverty alleviation. Secondly, poor CHD patients have been enjoying the favor. But patients with other diseases are still under enormous financial pressure. It is necessary to increase efforts to 
publicity for more medical subsidy. It is still a long way to health alleviation.

\section{Conclusions}

Our study found that the prevalence rate of CHD was increasing year by year. With the introduction of the health poverty alleviation project, the out-of-pocket ratio was less than before. And the loss of DALY was smaller and smaller. The project not only bringed healthy life expectancy to poor families, but also greatly reduces their financial burden. In conclusion, the implementation of the health poverty alleviation project could better reduce the burden of disease and protect poor families from potential impoverishment. This project increased the strength and cohesion of the masses of all ethnic groups. It also contributed to maintaining social stability and long-term stability.

\section{Acknowledgments}

The authors acknowledge the different local actors who have contributed to the interventions in the area and the research process; the First Affiliated Hospital of Nanjing Medical University and the Kizilsu Kirghiz Autonomous Prefecture People's Hospital. We are indebted to the local resident in Kizilsu Kirghiz Autonomous Prefecture for their kind collaboration in the data collection. Besides, the authors gratefully acknowledge the financial support of the National Natural Foundation of China, the hospital association Science Foundation and the medical association foundation of Jiangsu province, the support of the government of Kezhou.

\section{Authors' contributions}

Conceptualization and validation, Y,C.; Writing-original draft preparation, C.Z.; Writingreview \& editing, C.Y.L.; Investigation, A.G., A.M., and X.G.X.; Resources, Z.H.N. and X.P.N.

\section{Funding}

This research was funded by the hospital association Science Foundation of Jiangsu province, grant number JSYGY-2-2019-150; the key medical talents of Jiangsu province, grant number ZDRCA2016016; the pamir 3123 talents key project of Kezhou.

\section{Availability of data and materials}

All data generated or analysed during this study are included in this published article.

\section{Ethics approval and consent to participate}

Not applicable.

\section{Consent for publication}

Not applicable.

\section{Competing interests}

The authors declare that they have no competing interests.

\section{Author details}

${ }^{1}$ Department of Science and Technology, the First Affiliated Hospital of Nanjing Medical University, Nanjing 210029, China. ${ }^{2}$ Intensive Care Unit, the First Affiliated Hospital of Nanjing 
Medical University, Nanjing 210029, China. ${ }^{3}$ Department of Medical Records, Kizilsu Kirghiz Autonomous Prefecture People's Hospital, Artux 845350, China. ${ }^{4}$ Department of Medical Section, Kizilsu Kirghiz Autonomous Prefecture People's Hospital, Artux 845350, China. ${ }^{5}$ Emergency Management Department, School of Health Policy \& Management, Nanjing Medical University, Nanjing, Jiangsu 211166, China. ${ }^{6}$ Research Institute of Health Jiangsu, Nanjing Medical University, Nanjing, Jiangsu 211166, China. ${ }^{7}$ Outpatient \& Emergency Management Department, the First Affiliated Hospital of Nanjing Medical University, Nanjing, Jiangsu 210029, China. 


\section{Reference}

[1] Verguet, S.,Memirie, S.T.,Norheim, O.F., Assessing the burden of medical impoverishment by cause: a systematic breakdown by disease in Ethiopia. BMC medicine. 2016; 14:164.

[2] Kakkar, M.,Chauhan, A.S.,Bahl, T.,Rahi, M., Opportunities for One Health policies to reduce poverty. Revue scientifique et technique (International Office of Epizootics). 2019; 38:135-44.

[3] The presentation of precision poverty alleviation. [cited 2013 December 13]; Available from: http://www.gov.cn/ldhd/2013-12/13/content 2547546.htm.

[4] The, L., The best science for achieving Healthy China 2030. Lancet (London, England). 2016; 388:1851.

[5] Tan, X.,Zhang, Y.,Shao, H., Healthy China 2030, a breakthrough for improving health. Global health promotion. 2018:1757975917743533.

[6] Li, J.,Li, Y.,Moumouni, P.F.A.,Lee, S.H.,Galon, E.M.,Tumwebaze, M.A.,Yang, H.,Huercha,Liu, M.,Guo, H.,Gao, Y.,Benedicto, B.,Zhang, W.,Fan, X.,Chahan, B.,Xuan, X., First description of Coxiella burnetii and Rickettsia spp. infection and molecular detection of piroplasma co-infecting horses in Xinjiang Uygur Autonomous Region, China. Parasitology international. 2019:102028.

[7] The proposal of medical group assistance. [cited 2016 september 27]; Available from: http://www.gov.cn/xinwen/2016-09/27/content 5112792.htm. .

[8] Chen, C.,Pan, J., The effect of the health poverty alleviation project on financial risk protection for rural residents: evidence from Chishui City, China. International journal for equity in health. 2019; 18:79.

[9] Huang, L.Q.,Su, G.Q.,Zhang, X.B.,Sun, X.M.,Wu, X.J.,Guo, L.P.,Li, M.,Wang, H.,Jing, Z.X., [Key points of poverty alleviation of Chinese herbal medicine industry and classification of recommended Chinese herbal medicines]. Zhongguo Zhong yao za zhi $=$ Zhongguo zhongyao zazhi $=$ China journal of Chinese materia medica. 2017; 42:4319-28.

[10] The implementation of guidelines for supporting poverty alleviation in poverty-stricken regions. [cited 201819 August]; Available from: http://www.gov.cn/zhengce/2018-08/19/content 5314959.htm.

[11] The hospitalization expenses and epidemiology data in Kizilsu Kirghiz Autonomous Prefecture. . [cited 2019 November 25]; Available from: http://www.xjti.gov.cn/sjcx/tjnj 3415/. .

[12] Murray, C.J., Quantifying the burden of disease: the technical basis for disability-adjusted life years. Bulletin of the World Health Organization. 1994; 72:429-45.

[13] Yang, S.H.,Li, B.,Gao, L.,Li, N.H., [Prevalence and risk factors of chronic mountain sickness in Pamirs plateau]. Zhongguo ying yong sheng li xue za zhi $=$ Zhongguo yingyong shenglixue zazhi $=$ Chinese journal of applied physiology. 2018; 34:336-9.

[14] Mohanty, S.K.,Agrawal, N.K.,Mahapatra, B.,Choudhury, D.,Tuladhar, S.,Holmgren, E.V., Multidimensional poverty and catastrophic health spending in the mountainous regions of Myanmar, Nepal and India. International journal for equity in health. 2017; 16:21.

[15] Li, R.,Barker, L.E.,Shrestha, S.,Zhang, P.,Duru, O.K.,Pearson-Clarke, T.,Gregg, E.W., Changes over time in high out-of-pocket health care burden in U.S. adults with diabetes, 2001-2011. Diabetes care. 2014; 37:1629-35.

[16] Tobe, R.G.,Martin, G.R.,Li, F.,Moriichi, A.,Wu, B.,Mori, R., Cost-effectiveness analysis of neonatal screening of critical congenital heart defects in China. Medicine. 2017; 96:e8683.

[17] Kwon, E.,Park, S.,McBride, T.D., Health Insurance and Poverty in Trajectories of Out-of-Pocket Expenditure among Low-Income Middle-Aged Adults. Health services research. 2018; 53:4332-52. 


\section{Figure legends}

Figure 1. The distribution of extreme backward regions for combatting poverty in China. The red star in Xinjiang province is the study area.

Figure 2. The hospitalization expenses for poor patients in the People's Hospital of Kezhou. 


\section{Figures}

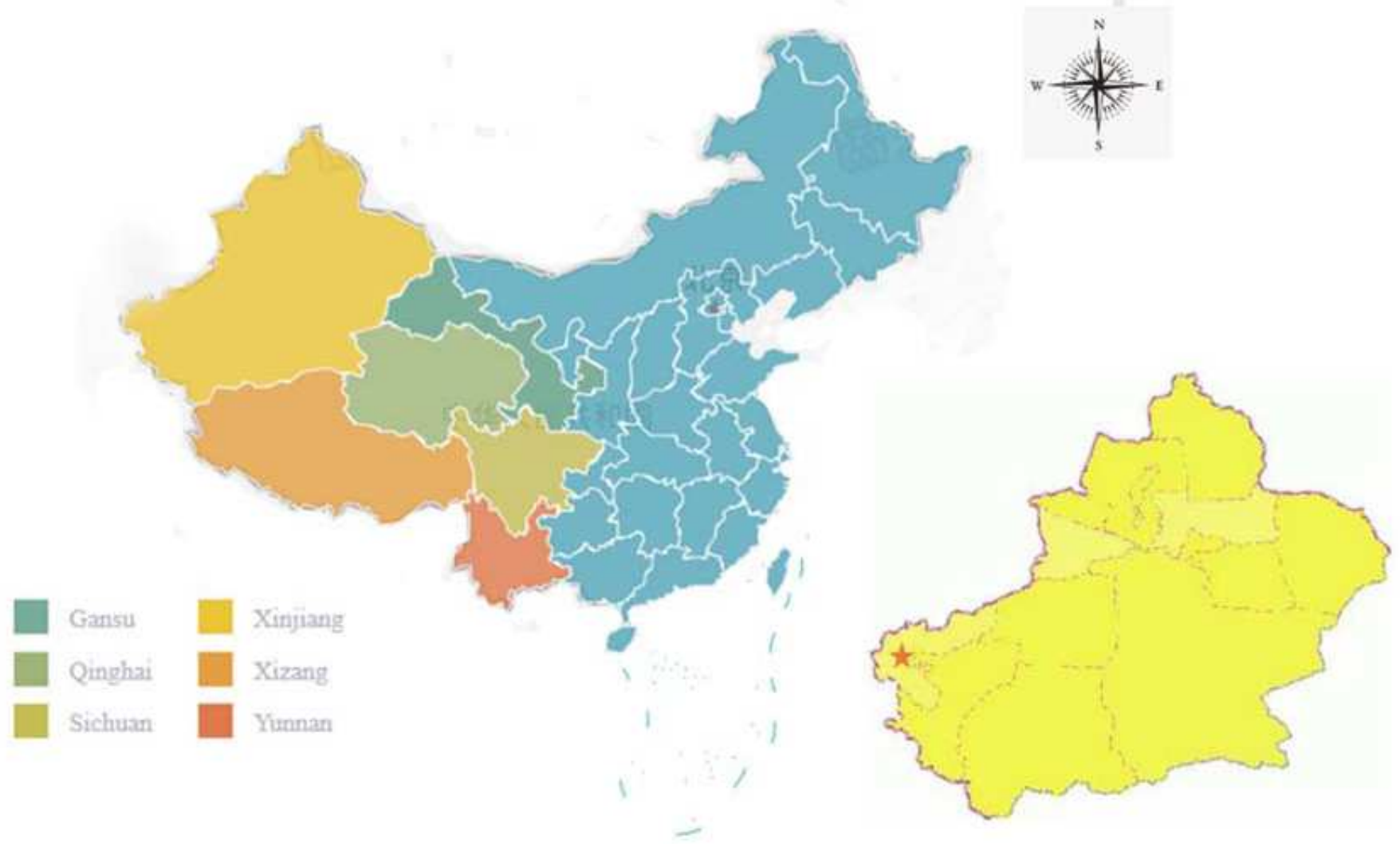

\section{Figure 1}

The distribution of extreme backward regions for combatting poverty in China. The red star in Xinjiang province is the study area.

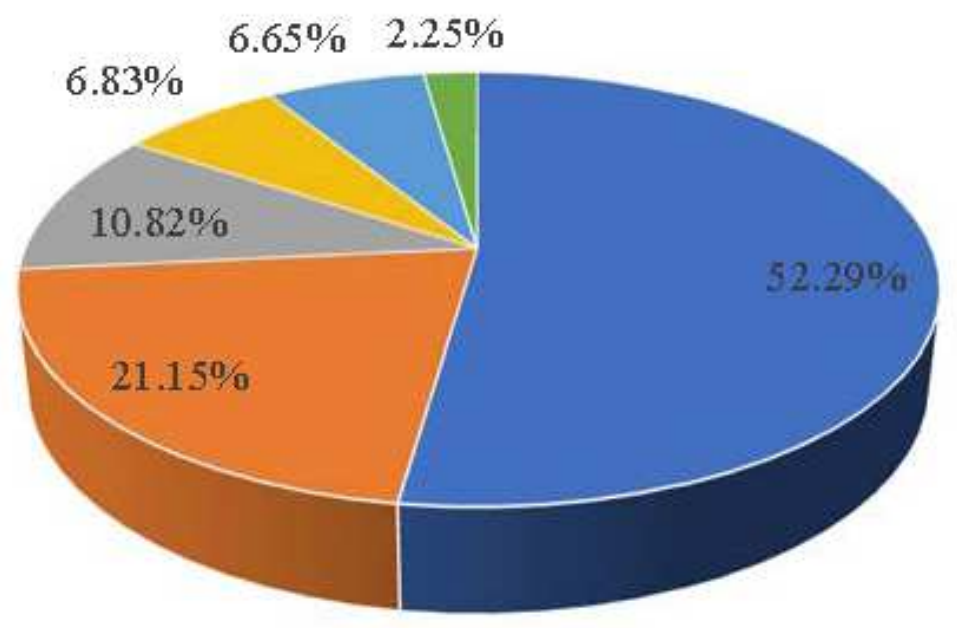

- medical insurance

- special fund for the poor

- commercial insurance

- relief from civil administration

- medical aid fund

- self-funded 
Figure 2

The hospitalization expenses for poor patients in the People's Hospital of Kezhou.

\section{Supplementary Files}

This is a list of supplementary files associated with this preprint. Click to download.

- Tables.pdf 